\title{
Greens and Greening: Agriculture and Restoration Ecology in the City
}

\author{
Steven N. Handel
}

$\mathrm{P}$ ush and shove, push and shove: today, most people in the world live in cities. We know they seek healthy lives. Restoration ecology can advance the quality of their lives, a greening of the urban sphere to advance a long laundry list of ecological services. Parallel to our work in restoration is a huge new movement to add agricultural activities in the urban core. This grew from the need to bring locally-grown fresh and affordable food into our cities, but has now added additional economic and social vitality to our cities that had been lacking. The need for food security is a foundation of our lives, but these urban islands of greens also show us they can supply recreation and leisure, new small business activity, and the charm of agricultural landscapes into our paved quarters, as well as, themselves, bringing many other ecological services.

At the same time, restoration ecologists in our cities have been consumed with ways to make that Great White Way into a Great Green Way. Can we find ways to make green streets in urban corridors link up our few parks? Can we introduce restored landscapes that also advance healthy living for our cities' people? We believe that ecological restoration and agricultural initiatives can be complementary and even synergistic as new components of urban planning, living systems to advance urban life.

Urban agriculture and urban restoration activities can even be mutualists, not competitors, for small land parcels. For example, so many of our crop plants need pollinators and other beneficial insects for fruit and seed production. Where will they come from, the \#7 train? Adjacency of small urban habitats can supply both nesting and feeding areas for the pollinator community, which is still quite biodiverse in our major cities. Eliminate small urban habitats and pollination can limit for our hopes of high crop yields. Conversely, eliminate nearby rows of flowering crop plants and urban pollinators can be stranded in a forage-poor mowed lawn in a city park. Although our large social bees, honeybees and bumblebees, can travel widely, the dozens of species of solitary bees so important for agriculture have

Ecological Restoration Vol. 34, No. 1, 2016

ISSN 1522-4740 E-ISSN 1543-4079

(O2016 by the Board of Regents of the University of Wisconsin System. smaller flight ranges. In this way, networked agricultural plots and urban conservation lands can act in partnership, sustaining both land-use types. Healthy pollinator populations need forage plants throughout their flight season and this is not always available in small urban parks. Nearby agricultural enterprises can fill the dance card of foraging needs, keeping urban bee communities provisioned through time. Food security is not just for the urban poor, but is also for these beneficial insects.

Restoration ecology is also tied to the concepts and theories of landscape ecology, particularly the impact of habitat scale and shape. Landscape ecology adds the spatial dimension to our equations of population dynamics and community structure. Not all species can live in small landscapes or in landscapes that are long and thin, overwhelmed by the edge affect which makes the whole sun-drenched parcel dry and hot. In urban areas where relatively small landscapes become available for restoration practice, we spend much time explaining that the forest primeval or the species mix that Native Americans once experienced is just impossible to rebuild. Urban agriculture production also is involved with scale limitations (see Pearson et al. 2010). We have seen, and many of us have participated in, micro-scale urban agriculture, using green roofs, backyards, and even fire escapes to grow a modest selection of homegrown veggies of which we are so proud. There is a meso-scale of urban agriculture which also supports our urban citizens. More and more throughout the world community, gardens as a social and culinary activity are sprouting up. From the allotment gardens of European cities to the block associations and social clubs in the Americas, initiatives and collaboration for growing produce supplies the local community and builds camaraderie as well as casseroles.

Finally, the macro-scale urban agriculture is becoming an important new land-use type within our cities. From vertical greenhouses, glass walled high-rises, to floriculture and vegetable greenhouses in our former industrial districts, to nurseries and small orchards which have metamorphosed abandoned brownfields into useful and healthy profit making landscapes; this is a new sector of urban commerce. We may now need a new taxonomy for urban land-use planning. The old sectors of commercial, residential, and infrastructure, are now ribboned with green zones to support all the others. In some cities, particularly in Asia, 
much of the produce for the urban population is grown next-door, not trucked in from the countryside. Informed planning for our urban centers now pays attention to the needs of kale as well as cabs. Do we have an irrigation source and proper lighting? Do we have a local transport network to deliver the foodstuffs? Can we manage and recycle organic wastes to keep urban soils healthy? Can we train and pay local agricultural workers adequately to keep the production line moving?

With very local urban agricultural systems we immediately have a visible informal education system for healthy diet and better public health. We also have ways to celebrate the culinary specialties of our diverse urban immigrant populations, helping to maintain community pride. We save money for citizens who have local food sources and do not have to subsidize significant transportation costs for their food supply.

These urban agricultural fields also partner with the work of restoration ecologists for environmental advantages. The urban heat island stress can be ameliorated by many patches of urban farms. Storm water can be redirected and cleansed to supply local irrigation sources through cisterns. This keeps storm waters away from urban waterways, lessening the erosion and the disturbance of flashy watercourses, allowing more natural riverine corridors. Ecologically restored habitats in the city improve air quality and lesson the noise and lack of aesthetic landscapes of highly paved city neighborhoods. Agricultural parcels play the same roles for the urban population.

In developing new models of urban design, our city planners and landscape architects have paid special attention to waterways and green corridors. Much of this design interest is for aesthetics and recreation. The new understanding of the importance of ecological services simply underscores the value of these elements on once paved areas. The equation of modern urban planning must include terms for urban agriculture and restored habitats, although it is unknown how they will be weighed algebraically to maximize the solution of sustainable urban living. We must find ways to incorporate these two worlds into our training, zoning regulations, and political perspectives quickly as the world's urban populations rapidly grow.

It is so difficult to wrestle with the constraints of urban restoration ecology to re-green our cities. But edible greens in the cities also are needed and ways to rapidly nurture this partnership is, literally, food for thought.

\section{Recommended References}

Alternative Framing Systems Information Center. Contains many links to information, including organizations, policy, and methods. afsic.nal.usda.gov.

Butler, L. and D.M. Moronek (eds) 2002. Urban and Agriculture Communities: Opportunities for Common Ground. Council for Agricultural Science and Technology Task Force Report, 138.

Hodgson, K., M.C. Campbell and M. Bailkey. 2011. Urban Agriculture: Growing Healthy, Sustainable Communities. Chicago IL: American Planning Association.

Local Governments for Sustainability. Consortium of municipalities around the world, sharing ideas for holistic approaches to improved urban living. www.iclei.org.

Lovell, S.T. 2010. Multifunctional urban agriculture for sustainable land use planning in the United States. Sustainability 2: 2499-2522.

Pearson, L. J., Pearson, L. and C.J. Pearson. 2010. Sustainable urban agriculture: stocktake and opportunities. International journal of agricultural sustainability 8(1-2):7-19.

Resources Centres on Urban Agriculture and Food Security. Gives an international perspective and ways that urban agriculture provides benefits. www.ruaf.org/about-ruaf.

University of California, division of Agriculture and Natural Resources. Typical of many university outreach sites, the UC site gives wide information for individuals and organizations interested in urban agriculture. ucanr.edu/sites/UrbanAg/

van Ginkel, H. 2008. Urban Future. Nature 456: 32-33.

Zasada, I. 2011. Multifunctional peri-urban agriculture-A review of societal demands and the provision of goods and services by farming. Land Use Policy 28: 639-648. 